\title{
Online Legal Service: The Present AND FUTURE
}

\author{
Md.Aminur Islam, Jannatul Ferdaus, Md. Abbas Ali khan and Md. Tarek Habib \\ Department of Computer Science and Engineering, Daffodil International University, \\ Dhaka, Bangladesh
}

\begin{abstract}
To find a lawyer becomes a headache for business organization or general people. Sometimes people face many difficulties to find proper lawyer as their requirements, because of information gap. In addition, it is also difficult to find experienced lawyer. Usually, in order to hire a lawyer people need to meet him physically which is time-consuming and expensive. The delivery of legal services remains largely fragmented, outdated, and inefficient. The main purpose of this paper is to do empirical research about how the Internet is currently failing laypeople who are searching online for the legal help to their life problems and what a future agenda of user-centered standards and practices for better legal help on the Internet could be. It initially looks at the existing literature about how the Internet can best be used as legal asset and the situation quo of lawful help websites. Then it metering and looks at negative client reports and Investigates of legal help websites. Finally, it presents the primary study of how people search for resources to solve a legal problem, how they scorn and counts legal aid services online, and their recompose on which existing lawful help websites they consider to be the most usable, the most faithful, and the most valued. This data is necessary to propose new best exercises about how these tech-based services can best serve people, in terms of usability, characteristic of service, and safeguard of the users' interests. It also ensures the importance of the Internet as a lawful help service and highlights the need for more experiment and development on better online legal service help websites that fit general people needs and preferences.
\end{abstract}

\section{KEYWORDS:}

Online Legal Serivce, Hire Lawyer Online, Search Lawyer Online, Legal Service Online Bangaldesh,Legal Technology, Procedural Justice.

\section{INTRODUCTION}

The technology has rapt the universe of juridical services and commitment to enhance how people entrance and explore the justice process. The Traders and researchers are call on for improvement of tech-based assets that aids general people explore their juridical issues [1]. Juridical futurist Richard Susskind focuses to the likelihood for online juridical services to democratize access to juridical services. It is early days to be sure, but inside few years these online juridical service systems will be commonplace in helping laypeople to identify when they need juridical help and to pick the best sources of counsel, as well as in actually offering them handy direction [2]. Online juridical services will create the law accessible to laypeople who would something else have no reasonable sources of juridical aid. This I call the accomplishment of the 'latent juridical market'- those numberless occasions in the lives of many laypeople when they need juridical help and would convenience from juridical help but, until now, people have been incapable to secure this assistance. Online juridical service, therefore, will free the latent juridical market. The commitment is that there can be a new generation of online lawful commodities and services that approve people to detect and explore juridical aid. There are calls for technology to rise the ability of civil juridical service providers to convention the juridical

DOI: $10.5121 /$ ijcsit.2018.10502 
requirements of all laypeople [3].Practitioner's attorney that much intellectual juridical technology be built, so that both lawyers and clients can increase their receptivity to resolve juridical problems and locate the ingress to justice gap [4]. Johnson trumpets the possible for online tools to authorize people to ingress juridical services and letting them 'defeats their fears of contracting with lawyers and the possible complicacies of juridical problems' [5]. These type of changes in technology will grant "an another source of reasonable juridical services aid fulfill the gap left by overloaded and reducing juridical aid groups". The vision is that online sites and instruments will let any individual with an Internet connection indicate juridical facts, find out her specific problem, and explore the juridical procedure to solution [6]. Furthermore, the prospect is that online juridical services will aid more people ingress juridical services that nowadays do. Scholars hope that tech based services will open up ingress to laypeople who nowadays have inconvenience engrossing juridical services, including those in village areas, without available time amid standard working hours, with dynamism restrictions, or without private transit [7]. Furthermore, tech-enabled juridical aid grants many conveniences over eyeball-to-eyeball service, together with scalability for service suppliers and benefit, sincerity, and lawyer cost for people. Further, there is a necessity for new ways to engage and backing user with juridical aid, particularly as current studies show that many laypeople with civil justice problems do no connect to experienced, such as law librarians, lawyers, courts, or otherwise, for aid with their problems [8].The ABA upheld fourteen a few entrance to equity ventures from 2012 to 2013 to created online juridical services for client [9].Different non picks up and revenue driven organizations have created mobile applications, web sites, and other programming software that objective to give benefit people group's juridical necessities. The clear description of the issue is to give online support to the online legal seeking person.

\section{LITERATURE REVIEW}

In characterizing client focused models for online legitimate help services, there is a constrained collection of research from attorneys, human-computer interaction scholars, sociologists that set out beginning understandings of how laypeople utilize the Internet to get to lawful help and what key fail points and chances exist.There are expanding quantities of lawful data sources and services available to the overall population online. Though data about the law and tools to finish lawful tasks were truly saved for legitimate experts, there has been an opportunity to developing these legal services available on the web, either for very low costor for free. The sorts of websites and their patrons include the following classes.

\subsection{GOVERNMENT/COURT-SPONSORED INFORMATION}

Sites that say what the law is, the thing that lawful techniques are, and what qualification for accepting administrations are. [10].Non-profit Legal Services Referrals/Information sites that assistance a client make sense of what their lawful issue is and what nearby services are accessible. [11]. Private Legal Information sites that assistance clients comprehend what the law says in regards to specific subjects. These incorporate destinations that present articles and replies on lawful issues, as Immihelp, Nolo, Upcounsil, and Hiremelegal, and in addition more legal advisor centered apparatuses that give top to bottom research instruments and rundowns, as CaseText, Judicata, Ravel, PlainSite, and CoCounsel.Legal Services/Eligibilitysites that present screener to figure out what legitimate services or ways clients may be qualified to seek after. Regularly these are controlled by philanthropies or new businesses. Cases of these destinations incorporate Expunge.io and Citizenship Works. Private Legal Self-Help tools that furnish the client with data as well as help them in getting frames finished or even to settle their question without experiencing the courts by any stretch of the imagination. Here, there are for the most part revenue driven new businesses like Bridge US, Modria, Legal Zoom and Rocket Lawyer. More laypeople are swinging to the Internet to discover help to determine issues with lawful 
measurements. The Internet is progressively a first port of require a man when searching out data about whether their concern is a legitimate one, and how to conceivably address it [12].A recent report 2010 from the $\mathrm{ABA}$ finds that an expanding number of individuals are utilizing on the web scans to discover a legal counselor for an individual lawful issue. The survey found that the vast majority, in the event that they required a legal counselor for an individual legitimate issue, would first swing to family, companions, and associates to discover a legal counselor and afterward contact a known legal counselor, look in a registry, or hunt online [13].Younger adults are especially likely to depend on web scans for finding a legal counselor, while not very many of those more than 65 would utilize the Internet to discover a legal advisor [14].

The survey asked into what online services a man would be destined to utilize if hunting down a legal advisor to help them. The individual was offered the alternatives of legal advisors' sites, social networks like Facebook \& twitter, an online catalog, a Q\&A site, a legal advisor rating webpage, sites or email list hosts. The most astounding number of respondents said they would likely utilize Q\&A sites, attorney rating sites, and legal advisors' own particular sites. Online indexes and coordinating sites positioned to some degree lower. Positioned very low were online journals, web-based social networking, and Twitter, Facebook, and list hosts [15]. At the point when individuals chose to continue on a lawful issue without an attorney, the ABA survey found that they were probably going to swing to free online services. Free online services positioned nearly as exceedingly as the utilization of court self-improvement focuses or judges. Free online administrations positioned higher than books, court agents, programming, or curators. Expensebased online lawful administrations were positioned the most minimal, as to the least extent liable to be utilized [16]. Free online lawful assets were especially prevalent among more youthful and lower salary respondents.

The ABA overview demonstrates that individuals do have a large enthusiasm for free on the web legitimate assets and unbundled lawful service that they could buy from legal counselors. It likewise demonstrates that for the errand of searching down an attorney, the Internet may not be their first asset, but rather it is more prominent among youngsters and is about as famous as looking through an offline storage. These patterns all demonstrate that the Internet as a wellspring of legitimate help regardless of whether it is being utilized for finding a legal counselor or exploring a lawful methodology without one is an imperative focus for taking a shot at enhancing access to equity, particularly among more youthful individuals and those in bringing down wage levels.

\section{METHODOLOGY}

We developed a web based system which name is CaseLaw. CaseLaw is an online platform for Lawyers and Clients from where client can post their cases and lawyer can submit proposal on cases and hired by client to handle cases. This system can store all previous job information that is helpful for client to find out experienced lawyer. Finding a lawyer sometime becomes a headache for business organization or general people. Sometimes people face many difficulties to find proper lawyer as their requirements, because of information gap. In addition, it is also difficult to find experienced lawyer. Usually, in order to hire a lawyer people need to meet him physically which is time-consuming and expensive. The delivery of legal services remains largely fragmented, outdated, and inefficient. Suppose a person resides outside Dhaka Now, if he meet to deal with a case from Dhaka Supreme Court then he must come to Supreme Court physically. This takes times and also expensive. To solve this problem CaseLaw provides a platform which enables the person finding proper lawyer sitting at home. The person can find lawyer based on their experience, qualification, and region and can hire remotely.

Business process model represents the social and economic value. The most part of the business model is how to revenue from the model. CaseLaw has small revenue part. 


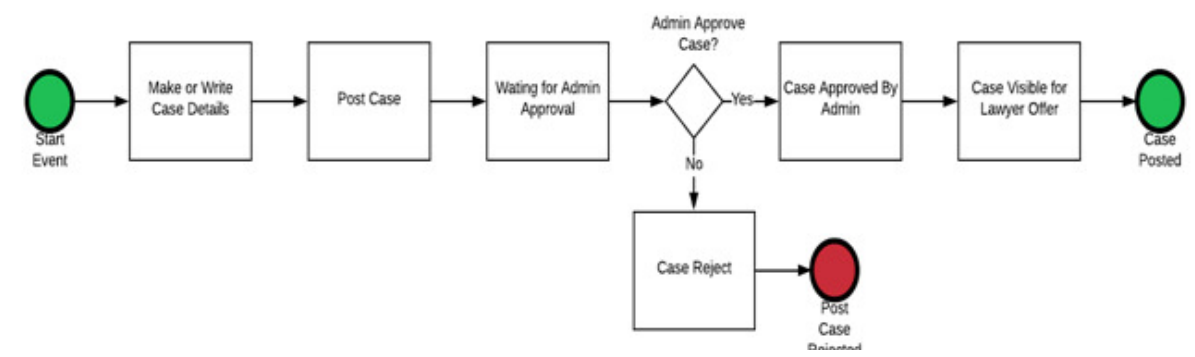

Figure 1: Business process mode.

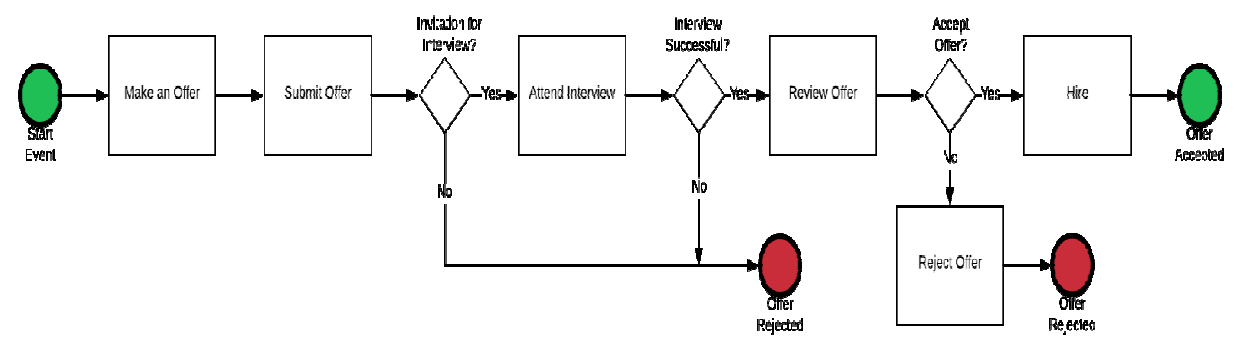

Figure 2: Business process model.

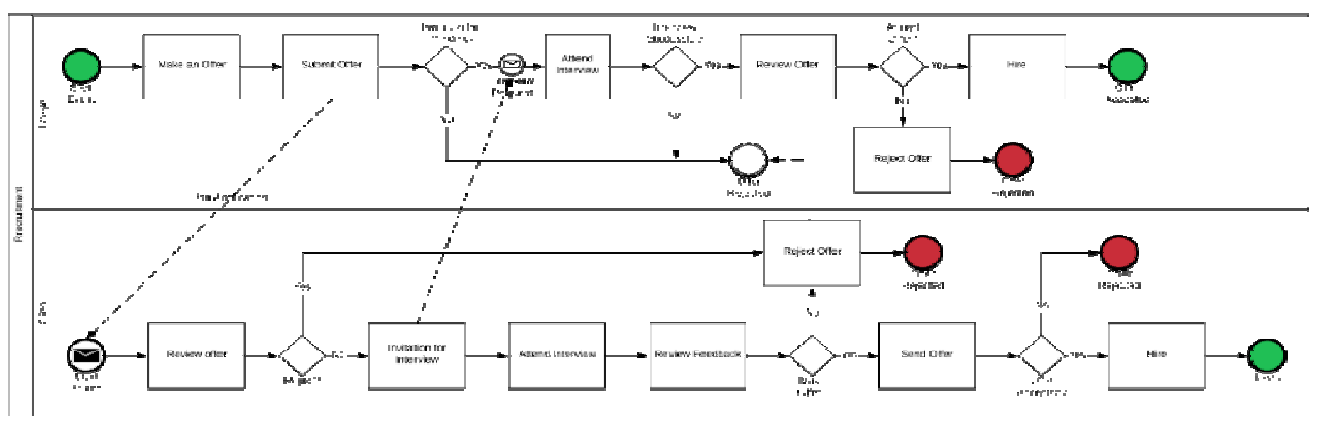

Figure 3: Business process model of how a client handle lawyer offer/bid on case and hire lawyer.

\subsection{Logical DATa Model}

The logical data model represents the data processing modules. It used for data analysis and processing easily. The Entity-Relationship Diagram/Model represents the logical data model. Our Web Application is Dynamic, this function works by using the internet. A database is needed for storing and retrieving data. The internet is a most important role in our application. For ensuring security there is a DBA (Database Administrator) who can only access the database. The following figure 4.1 shows the relationship between the user and the system.

\subsection{INTERACTION DESIGN AND UX}

User Experience (UX) is critical to the success or failure of a product in the market. Interaction Design is most important part of User Experience (UX) design. An application fruition depends on User satisfaction. How an application is more attractive to the user is depends on. The 
following figure 4.2 shows there are 7 factors that describe user experience, according to Peter Morville.

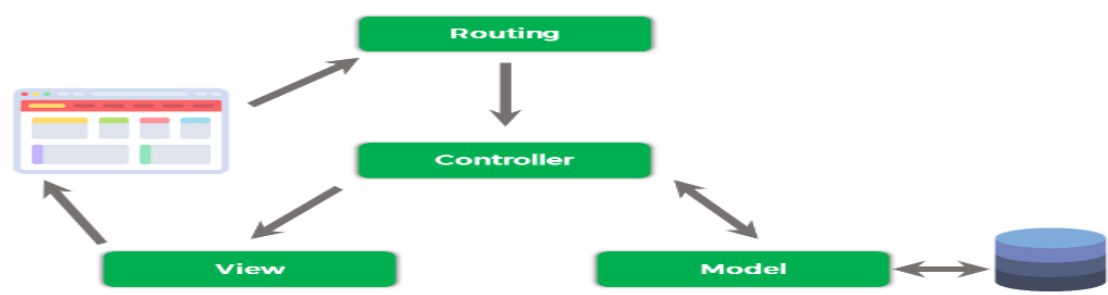

Figure 3.1: Request lifecycle.

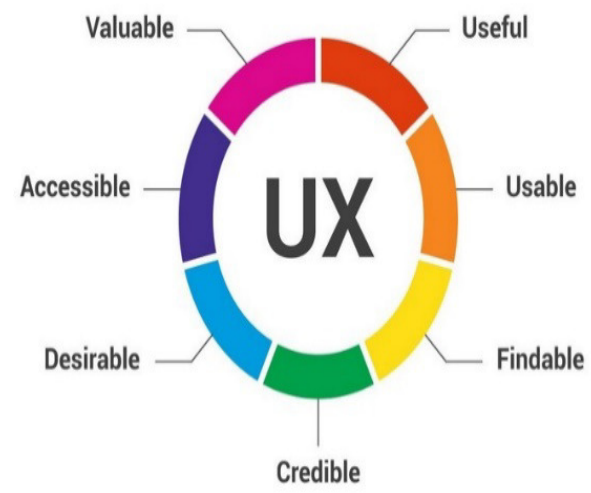

Figure 3.2: The 7 factors that influence user experience.

\section{The Future of OnLine Legal Service}

Technological innovation has prompted more institutionalized answers for the conveyance of lawful procedures and the capacity to products numerous lawful administrations. Various legitimate tech organizations, colleges and law offices are presently investigating the degree to which the subjective area of legal advisors can likewise be computerized. As indicated by Riverview, 'an essential target is to mechanize a portion of the subjective capacities of information specialists to furnish associations with wise choice help apparatuses' (Hyde 2015). Riverview is right now working with Liverpool University in an offer to apply computerized reasoning (AI) to lawful assignments. The joint wander will perceive how far the AI skill of Liverpool University's software engineering office can be utilized as a part of a business law office. This wander returns on the of Hodge Jones and Allen's work with scholastics from University College London (UCL) to make programming that evaluates the benefits of individual damage cases. A teacher of financial aspects and monetary estimation at UCL analyzed 600 cases finished up finished a year time frame utilizing measurable procedures to decide the elements adding to progress or disappointment and level of harms and expenses. The outcome was a gadget that can ascertain the feasible results of individual damage cases. The associations close to home damage group administrator said the demonstrating 'tested some of our partialities about the cases we ought to go up against' (New Law Journal 2014: on the web). Advanced machine perusing programming has demonstrated speedier and more exact than a specialist in conveying equivalent lawful administrations and choices guidance. As right on time as the 1970s Weizenbaum (1976) contended that PCs should not to settle on legal choices, despite the fact that they could possibly do as such. Berman and Hafner (1987) examine various reasons why lawful 
choices can't be clarified by any manage based model of law, however mind boggling. The legitimate chief applies existing tenets, as well as is frequently called upon to inventively adjust rules, to pick among contending rules, and to make new standards (Gardner 1985). Master frameworks can be utilized as a part of the administration of algorithmic basic leadership how much this utilization meets moral and nuanced understandings of cases stays to be seen yet these frameworks can likewise be utilized to sort out and show the important actualities and issues in the administration of human chiefs (e.g. IBM's Watson and ROSS frameworks).It is likely the joining of data and advanced innovations into criminal lawful practice and the activity of the courts will reshape the conduct designs and the reasoning procedure of partners in the criminal lawful field, from judges and legal advisors to court assistants and staff in legitimate firms. The esteem and possibility of virtual court frameworks in England and Wales has been talked about on various events as a major aspect of the Ministry of Justice's advanced methodology. A move to e-revelation and digitalized CPS/criminal case forms has officially changed criminal legitimate practice. By 2020 digitization looks set to additionally affect criminal legitimate specialists both regarding how conventional cases are led, and through new digital wrongdoing and innovation laws

\section{Case Study}

Singapore as of now has set up an Electronic Litigation System which has been asserted to help accomplish viable, proficient and temperate administering and organization of equity (http://www.supcourt.gov.sg/). As right on time as 1996, the Singapore frameworks persuaded some 'IT clever legal advisors' to experiment with utilizing e-docs in the Technology Court for both criminal and common trials. In 1998, the utilization of e-docs was reached out to all interests heard in the Court of Appeal and in Magistrates' Appeals (managed by the Chief Justice). What's more, in 1999, the utilization of e-docs was stretched out to every single criminal trial and chose common trials. This was made conceivable when every one of the courts and chambers in the Supreme Court Building were completely prepared to help the utilization of e-docs through level screen screens on rotatable arms, video exchanging gadgets and custommade podiums, all making the courts e-docs fit.Online dispute resolution (ODR) is being touted as a region with gigantic potential for addressing the necessities of the legitimate framework and its clients. It's mean to expand access to equity and resolve debate all the more effectively, rapidly and efficiently is as of now being effectively incorporated by destinations, for example, eBay, Cybersettle and the Canadian Civil Resolution Tribunal. For low esteem guarantees, the present court framework can be expensive, moderate, and complex, particularly for defendants face to face. The Online Dispute Resolution Advisory Group, set up by the Civil Justice Council, investigated the capability of ODR for common question of significant worth under $£ 25,000$. The gathering's principle suggestion is that HM Courts and Tribunals Service build up another, web based court benefit, known as HM Online Court (HMOC): 'On HMOC, individuals from the Judiciary would choose cases on an online premise, connecting electronically with parties. Prior determination of question on HMOC would likewise be accomplished through crafted by people we call 'facilitators' (ODR Advisory Group 2015: 6). The gathering recommends three levels: online assessment (guidance); online assistance (intercession); and online judges (overseeing and choosing cases) (Hodges 2015). Numbers in the present little claims framework have contracted from 60,000 of every 2001 to an insignificant 25,000 of every 2014. That use is 'overshadowed by the 500,000 question handled in 2014 in the ombudsmen framework, which have kept on ascending for a few years' (Hodges 2015). Hodges (2015) takes note of that 'it is as of now settled that purchasers who have question with merchants are more pulled in to ombudsmen than to courts or administrative protest capacities'. Inquiries concerning the suitability of a court-based ODR framework point to the missing human component, the requirement for discourse, and the significance of unloading where terms and assertions may have been misconstrued. But then, eBay's ODR framework is conceivably a standout amongst the best contentions for taking a 
gander at extending where and how these procedures are actualized. Around 60 million contradictions among merchants on eBay are settled each year utilizing (ODR Advisory Group 2015: 11-12).

\section{CONCLuSiON}

This empirical study of how laypeople utilize the Internet to react to issues with lawful issues avows the significance of client encounter outline and characterizes an underlying arrangement of client prerequisites for better methods of online lawful administrations. Following this underlying investigation of a restricted statistic, and of a specific sort of lawful errand, there is requirement for additionally investigation of laypeople's encounters with online legitimate help administrations. The client needs, inclinations, and work processes archived here can be checked in more broad observational and ethnographic future investigations. Future endeavors can likewise test the bits of knowledge by really fabricating innovations upon them, setting them in the hands of non-legal advisors, and testing whether clients' understanding, engagement, and finish on legitimate errands are enhanced by new, client focused plans of lawful help administrations. This investigation establishes a framework of bits of knowledge and necessities which ensuing examinations must test and grow. This Article additionally can be utilized as the initial phase in an outline procedure that outcomes in the formation of new models of lawful administrations. The client necessities and discoveries can fill in as foundational experiences for originators and engineers, who are occupied with making higher quality online legitimate help. The outline ideas talked about in the Takeaways session offer some encouraging headings for usage centered associations to seek after. The client research and outline ideas in a perfect world will be utilized to model new sorts of legitimate data destinations, record get together devices, debate determination stages, and other online lawful administrations. Testing of these new models will likewise add to scholarly talks of what sorts of introductions and instruments are best in connecting the entrance to equity hole. To convey advancement to the entrance to equity development, there should be more observational investigation of what diverse gatherings of laypeople require and incline toward when utilizing innovation based assets, and in addition improvement of these new devices. This two-track way to deal with advancement will convey on the colossal guarantee that moderate innovation, productive information systems, and intelligent plan has for individuals' capacity to explore the lawful framework proficiently and successfully.

\section{REFERENCES}

[1] Rethinking Access to Justice । James J. Sandman | Hawaii Access to Justice Conference http://www.hawaiijustice.org/hajc/access-to-justice-commission/2014-access to-justice-conference Litigant Portals Provide a New Approach to Help Self-Represented Litigants http://www.ncsc.org/ /media/Microsites/Files/Trend \%202015/LitigantPortals_Clarke.ashx Last Access: 01 March 2018

[2] TOMORROW'S LAWYERS: AN INTRODUCTION TO YOUR FUTURE By RICHARD SUSSKIND. (90-91)

[3] Using Technology to Enhance Access to Justice by JOHN GREACEN(243-44) http://jolt.law.harvard.edu/articles/pdf/v26/26HarvJLTech241.pdf Last Access: 01 March 2018

[4] Software Usability and Legal Informatics by Anna Ronkainen https://papers.ssrn.com/sol3/papers.cfm?abstract_id=2162380 Last Access: 01 March 2018

[5] Leveraging Technology to Deliver Legal Services by Chris Johnson http://jolt.law.harvard.edu/articles/pdf/v23/23HarvJLTech259.pdf Last Access: 02 March 2018

[6] Web-based Legal Services Delivery Capabilities, in Using Technology to Enhance Access to Justice by Jane Ribadeneyra http://jolt.law.harvard.edu/articles/pdf/v26/26HarvJLTech241.pdf Last Access: 02 March 2018 
International Journal of Computer Science \& Information Technology (IJCSIT) Vol 10, No 5, October 2018

[7] Just a Phone Call Away: Is Telephone Advice Enough, Nigel J. Balmer https://www.researchgate.net/publication/254322617_Just_a_phone_call_away_Is_telephone_advice_ enough Last Access: 03 March 2018

[8] ACCESSING JUSTICE IN THE CONTEMPORARY USA, REBECCA L. SANDEFUR https://papers.ssrn.com/sol3/papers.cfm?abstract_id=2478040 Last Access: 05 March 2018

[9] http://www.americanbar.org/groups/legal_aid_indigent_defendants/initiatives/resource_center_for_ access_to_justice/resources---information-on-keyatj issues/grants.html Last Access: 010 March 2018

[10] USCIS http://www.uscis.gov/ Last Access: 10 March 2018

[11] https://www.illinoislegalaid.org/ Last Accesss: 10 March 2018

[12] Comment to Immigration Direct, CONSUMER AFFAIRS, Dieter of South Dartmouth, MA(2013) http://www.consumeraffairs.com

[13] Comment to Immigration Direct, CONSUMER AFFAIRS, Ernst of Miami https://www.consumeraffairs.com/legal/immigrationdirect.html

[14] Comment to Immigration Direct, CONSUMER AFFAIRS, Christine of Durham, NH https://www.consumeraffairs.com/legal/immigrationdirect.html

[15] Comment to Immigration Direct, CONSUMER AFFAIRS, Martin of Morgan Hill, CA https://www.consumeraffairs.com/legal/immigrationdirect.html

[16] Data Collection in a Flat World: The Strengths and Weaknesses of Mechanical Turk Samples https://papers.ssrn.com/sol3/Delivery.cfm?abstractid=2016308 lastAccess: 07 March 2018 